\title{
GLOSARIO DE REVISTAS
}

El Teatro del Mirlo Blanco

En un articulo reciente para La Nación de Buenos Aires, Enrique Diez Canedo ha revelado el comienzo de una interesań́e realización teatral. En Madrid, en casa de la Tamilia Baroja, y por obra del enlusiasmo de doña Carmen Monné de Baroja, esposa de don Ricardo, spintor, dramaturgo y hombre de variadisimas aptitudes, hermano de Pio Baroja, el gran novelisla, ha principiado a luncionar en los primeros meses del año el Teatro del Mirlo Blanco. El 7 de Febrero. en efecto. han comenzado las representaciones de que Diez Canedo da cuenta en su arliculo.

-El escenario-nos dice el autor-está dispuesto en un fondo de salón. rincón intimo. techado más bajo que el resto de la pieza, porque otra pequeña habitaciōn superpuesta, que se abre en galeria al ámbito mayor, le corta la mitad de la altura. Poco más alto es el escenario que un hombre puesto en pie: y la profundidad lampoco es mucha, como puede comprenderse,. En tan breve espacio de terreno se ha hecho mucho. Diversos artistas, presididos por Ricardo Baroja. han pintado decoraciones llenas de novedad y atracción. Siendo tan pequeño el escenario, uno de los trabajos más considerables ha sido ampliarlo, al menos para fáciles efectos de óptica, por medio de procedimientos eficaces Sucesivamente hemos visto aparecer en ese escenario una sidrería v́asca, un café madrileño de barrio, una botica de pueblo, una estancia de un enfermo y la de un moribundo, el gabinetc intimo de un hipnolizador. En el caso del café madrileño, una disposición ingeniosa sugería, tras el primer recinto. otros más amplios., .Claro está-agrega Diez Canedoque la tendencia simplificadora, impuesta no sólo por limitación de local sino por el sabor moderno que se ha intentado dar a las decoraciones, era la predominante.,

Pero ya es tiempo de que 
nos ocupemos de las piezás qué se han llevado a la escena del Mirlo Blanco. Sólo un autor extranjero-dice Diez Canedo -el norteamericano O. Henry. ha sido representado en $\mathrm{El}$ Mirlo Blanco: el diálogo :Miserias comunes, en que un ladrón reumático penetra en la habitación de un enfermo de reuma. a quien ya se le pasa el alaque. y la común enfermedad une los ánimos de aquellos dos hombres que parecian llamados a no entenderse en el terreno de lo tuyo y lo mio.s .Una aulora. Beatriz Galindo (seudónimo de doña Isabel Oyarzábal de $\mathrm{Pa-}$ lencia). ha dado un apunte de drama sintélico.. Otro autor que ha llegado hasta el Mirlo Blanco es Cipriano Rivas Cherif, excelente traductor de obras ilalianas, y artista a quien los problemas del teatro siempre han inleresado de manera vivisima. Su obra es un epaso de grand guignol, llamado «Trances. Ricardo Baroja, por su parte, ha contribuido con un cuadro titulado «Marinos vascoss, a cuya vigorosa emoción alude Diez Canedo con términos especiales. Valle Inclán también ha contribuido a la iniciativa con algunos fragmentos de su obra Los cuernos de don Friolera.. Pero el autor más importante que ha llegado hasta las tablas del Mirlo Blanco es Pio Baroja. De él se han representado dos obras: «Adiós a la bohemias. diálogo que figura en el libro titulado Nuevo tablado de Arlequin, y ya representado por Mercedes Pérez de Vargas; y .Arlequín. mancebo de botica o los pretendientes de Colombinas. Esta obra fué escrita por Pio Baroja especialmente para el Mirlo Blanco y ha sido calificada por Diez Canedo como la obra maestra de este teatro familiar. El critico agrega: .Los personajes de la comedia italiana vuelven a hacer sus muecas de amor y de broma en la larsa del autor de .El árbol de la ciencia. Un Pio Baroja humorista no es, propiamenle. una novedad. Pero un humor tan risueño, tan despreocupado. tan fácil para la expresión vivaz. tan vigorosamente animador de los tipos de prelendientes, el medicastro, el albéilar, el gendarme. del gracioso lacayo y la empingorolada condesa, del boticario Pantalón, padre de Colombina. y del aturdido mancebo Arlequín, cuya aristocrática cuna se descubre al final. no habia dado, tal vez. fruto tan espontáneo y gracioso en la obra del novelista vasco,s

No es esto todo: el propio Pio Baroja subió a la escena y desempeñó un papel de importancia en su farsa, el de Señor Pantalón, siendo secundado en el de Arlequin por Cipriano Rivas Cheril. Diez Canedo termina su artículo con las siguientes palabras: $\nmid$ B Buen capitulo para la biografia del 
shombre humilde y errantes. del humorista a veces malhumoradol Pio Baroja. y los actores del Mirlo Blanco, señorita Nalividad González, señoras Bach de Goldenberg. Juan de Benito, de Palencia, de Caro. de Abreu, señores Baroja (R.). Rivas Cherif, Garcia Bilbao. Vighi y de la Fuenle, merecen ver consignados sus nombres en el frontón del lemplo de Talia.s.S.

\section{El dandysmo de Baudelaire}

La figura de Baudelaire no ha pasado del todo en el film vertiginoso de la actualidad. Las modernas generaciones francesas le tienen, es cierlo. un poco olvidado, pero eso no quita que sea para muchos jóvenes escritores $y$ artistas un nombre respetable. Fuera de Francia, su influjo es seguramente mayor. Para algunos amaleurs chilenos. Baudelaire sigue viviendo una existencia esencial y pristina. Dios que merece todos los holocauslos. tiene un culto, con ritos propios y especiales.

Un escritor francés que no ha sido del todo infiel a Baudelaire, Estanislao Fumet, ha publicado recientemente un estudio sobre el dandysmo en el poeta de 'Las flores del mal, : No dice cosas que sean enteramen- te una novedad para el buen conocedor de la obra baudelairiana, pero su arliculo tiene un interés innegable. Desprendamos de él algunos acápiles.

Fumel comienza por decirnos que el maestro squeria embellecer la vida y la naturalezas, anhelo que se oculta en el corazón de todo poeta. Pero el medio que preconizaba Baudelaire no es el más común. Su dandysmo-escribe Fumet-era la doctrina del progreso personal. en oposición al pseudo-progreso mecánico que las democracias no dejan de hacernos sentir., Según Baudelaire hay sólo un progreso posible para el hombre consciente de su propia esencia. Es el que le edesembaraza del mal morals: doctrina que lleva aparejadas muchas peregrinas consecuencias que es interesante reseñar. EI dandy - dice Fumet-aspirará, entonces, a lo sublime. Elevará su corazón. lo distraerá, por los pensamientos metafisicos y por la voluntad de la caridad divina, de los sentimentalismos fáciles y minimos.s Sus ademanes - agrega - serán medidos. armoniosos y prolestarán contra toda infame vulgaridad. Moral de lo bello. sin duda. pero de lo bello tomado en su esencia, como equivalencia o irradiación del bien.,

Tenemos ya definido de ma-

- Forma parle este trabajo de un libro de Fumet, titulado -Notre Baudelaire. lanzado a la publicidad hace poco por la colección .Le voseau dior s. 
nera bien precisa un aspecto que se halla en muchos episodios de la vida de Baudelaire y que informa buena parte de su obra. Muchos años más tarde, en buena lengua castellana. Azorín nos dirá lo mismo que Baudelaire: -Ocultad vuestros dolores; haced bella y fuerte la vida., $\mathrm{Y}$ en esla breve sentencia reconoceremos el eco de las voces de los estoicos, viejas como la civilización occidental y acaso como lodas las civilizaciones. Fumet resume su pensamiento en las siguientes líneas: . En una palabra, el dandysmo es el esloicismo. El estoicismo del siglo diecinueve. Una anlecámara del cristianismo para los hombres muy delicados y para los suicidas fracasados,:

Oportuno es entonces recordar que en el número de éslos se halla Baudelaire. A los veinticuatro años. Baudelaire, joven genial, a quien más de una desgracia de familia hacia sentir sobre sus espaldas el peso de una soledad perfecta, alentó contra su vida. ¿Por qué prelendió malarse? El mismo nos lo dirá: - Me mato porque soy inútil a los demás y peligroso para mi mismo.s Pero lo más curioso de lodo es que pretende matarse lambién porque es creyente... He aquí un católico que no cumple de manera muy fiel los mandatos de su comunión. Liberarse de la vida es para él la culminación de su dandysmo intimo. Pero suicidarse es, para la religión, un pecado que no fiene dispensa alguna.

Pero esto no es lo más importante: veamos entrelanto algo más del dandysmo de Baudelaire. llevado, como se ve, hasta sus últimos extremos por el joven poeta. Muchas cosas le parecen a Baudelaire condenables y dignas de excecración. Su criterio de dandy le alejará no sólo de lodo aquello que forma lo patético vital: las emocioncs, las pasiones. los extremos políticos, sino lambién de aclividades sociales como el comercio. Nadie le pide al poeta que sca comerciante, sin duda. pero el poeta nos dice: El comercio es satánico, porque es una de las formas del egoísmo. y la más baja, la más vil., Todo en Baudelaire es desprecio de la cantidad por la calidad. No acepta que se piense en rebaño, que los hombres se congreguen para ocuparse de un asunto común. Lo excepcional y privativo es lo que desea su espiritu. Fumel dice que si el pocta manifiesla un sentido tan estricto en lo que se refiere a puntos que no le tocan de cerca, cuál no será su estriclez si se Irata del arle. Y agrega más adelanle esta pequeña pregunta profunda: ‘¿Cuántos de aquéllos. tan numerosos. que admiran a Baudelaire. le siguen hasta donde va él?

Los pensamientos de Baude- 
laire sobre cl arle son ya más conocidos, y han sido divulgados por sus discípulos y seguidores. no siempre con mención especial del poeta. Deseaba el maestro del parnaso que los menesteres del arte fueran palrimonio de unos cuanlos hombres a quienes se pudiera confiar lal tarea. Estos eran para él los verdaderos arislócrafas, es decir, seres refinados y exquisitos que habian llevado el dandysmo a lo más intimo de su alma. El artista se halla, para Baudelaire, solo en el mundo, y la multitud lo excecra. Recuérdese aquel admirable, aquel maravilloso poema en que una madre. grávida de un hijo que va a ser artisla, increpa al cielo por aquella smaldición.. El dandy completa su ciclo con muchas otras expresiones asi, en verso y en prosa, que revelan el fondo de su pensamiento. Su arte es un arte distinguido, de guante blanco. La inmulabilidad es patrimonio de muy pocos. A la multitud la enloquecen lo patético, el gesto desenfrenado y el grilo $\sin$ medida.

Pero para Baudelaire pasan los años brillantes de la juventud, en los cuales podia hacer el cuadro integral de su dandysmo. No sólo era dandy en lo que se refiere a sus sentimientos, a su arte, a su vida. También lo era en el vestir. Sus biógrafos nos han dejado de él una imagen perfecta. Veslia con un buen gusto propio $y$ personal que, por el hecho mismo de no ser el común, parecia exagerado. El mejor sastre y los más afamados camiscros y sombrereros abastecian su guardarropa. No era Baudelaire hombre de fortuna. pero lodo aquello que ganaba. o casi lodo. se convertia en corbatas, redingotes y bastones de puño de oro. Llegado a la madurez, madurez un poco gastada, acaso vejez prematura, no le queda al pocta otra cosa que su dandysmo interior. Solo. como siempre vivió. exagerando un poco el sentimiento de su soledad, ya no se le ve como antes lucir la levita mejor corlada o el bastón más hermoso. Pero su espiritu sigue, hasta el úllimo día de su vida, alentado por la distinción que le erguia por sobre sus contemporáneos.

Fumet termina su arliculo con un oporluno recuerdo de algunas palabras de Jesús a sus discipulos. Cuando ayunèisdice el Maestro - no debéis presentaros demacrados, como los hipócritas, que extenúan su semblante para que se suponga que un prolongado ayuno les lienc asi.: Baudelaire reconoce en Jesús un antecesor de su dandysmo, no el primero. sin duda, si se recuerda la escuela esloica, pero si uno de los más destacados. - $\mathrm{S}$. 